\author{
Anera Stopfer \\ Filozofski fakultet \\ Sveučilište u Zagrebu \\ anera.stopfer@gmail.com \\ (D) https://orcid.org/0000-0001-9267-4325
}

\title{
Kazalište i dramski tekst na festivalu Croatie, la voici u Francuskoj
}

\section{Theater and drama text at the festival Croatie, la voici in France}

Sažetak: U radu je analiziran primjer provođenja hrvatske vanjske i kulturne politike osmišljavanjem i organizacijom festivala Croatie, la voici koji je održan u Francuskoj Republici u jesen 2012. godine kao rezultat međudržavnih dogovora između Hrvatske i Francuske. Festival je organiziran po principima francuske kulturne diplomacije te je potaknuo razmjenu umjetničkih praksi i djela, čime je pogodan za ispitivanje učinaka mobilnosti u kulturi. Kroz istraživanje ove manifestacije promatrano je na koji način su se ojačale veze između Hrvatske i Francuske u području kazališta i dramskog pisma. Opisane su i analizirane aktivnosti koje su ostvarene u pripremi i provedbi segmenta festivala u onom dijelu programa koji se odnosio na kazalište i dramsko pismo propitujući kako model ovakvog primjera kulturne diplomacije doprinosi poticanju mobilnosti unutar kulturnog i kreativnog sektora i samim time u jačanju međudržavnih suradnji i veza.

Napravljena je analiza programa koji su ostvareni u području kazališta i dramskog pisma tijekom Festivala, popisane su uključene organizacije u pripremu i provedbu tih programa, broj uključenih hrvatskih umjetnika, broj izvedbi pojedinih predstava i programa, te su prikupljeni podaci o posjećenosti. Provedbom online upitnika, utvrđena je pozitivna praksa provedbe studijskih posjeta koje su izravni učinak pripreme Festivala na mobilnost umjetnika i profesionalaca u području kazališta i dramskog pisma te su dobiveni podaci stavljeni u komparativni međuodnos kako bi se pridonijelo analizi o produbljivanju veza nastalih zahvaljujući Festivalu. Analizirani su podaci o suradnjama između dviju zemalja u području kazališta i poticanja dramskog pisma koje su podržane proračunom hrvatskog Ministarstva kulture tijekom Festivala te tijekom tri godine prije održavanja Festivala i tri godine nakon njegove provedbe. Zbog uzročnoposljedičnih odnosa koji su predmet analize, rad nosi karakteristike eksplanatorne studije. Po istraživačkom pristupu, riječ je o intrinzičnoj studiji slučaja.

Ključne riječi: kulturna diplomacija, međunarodna suradnja, kulturna politika, festival, mobilnost 
Summary: To better present one's own ideas and agendas, one requires understanding of other cultures and everyday realities. In order to understand the numerous cultural specificities that can stimulate more direct dialogues between countries and enhance mobility of ideas, knowledge and intercultural perspectives, a domain of cultural diplomacy has been developed in the field of international cultural cooperation, combining the goals of cultural and foreign policies. Cultural diplomacy can be defined as the exchange of ideas, arts and other aspects of culture between countries in order to foster mutual understanding (Schneider, 2003). In an increasingly dynamic environment that is facing global challenges, new forms of collaboration between artists, professionals, non-governmental and intergovernmental organizations, the private and public sectors, both nationally and internationally, needed to be developed and the beginning of the 21st century saw research studies and analyzes of contribution and importance for cultural diplomacy in daily life and its reflection on the economy (Feigenbaum, 2001). In the name of developing bilateral relations, France saw great potential in developing international cultural projects, programs and activities, and thus became the cradle of cultural diplomacy. It is the instrument of the Cultural Seasons which serves to inform the French public about the culture of a certain country and vice versa, and is based on the principles of reciprocity and bilateral cooperation. Using the example of the Croatian Cultural Season, which took place in the autumn of 2012, this paper describes the specific ways of preparing and implementing this mechanism of cultural diplomacy, which included the institutions of the Republic of France and the Republic of Croatia. Research contributes to the analysis in the under-researched area of cultural policy in domain of cultural diplomacy and explores some of the potential ways to improve mobility in cultural sector. This paper consolidates and systematizes information on the preparation and implementation of the Croatian Cultural Season in France and actions that were taken in preparation of programs related to performing arts and dramaturgy and contributes to the analysis of the effects that this form of cooperation has achieved in international exchanges. Case study was used as the research strategy.

An analysis of the programs achieved in the field of theater and drama during the Festival was made, information on those involved in the preparations was described and proved, as well as the information on the number of Croatian artists involved, the number of performances of individual plays and programs, along with the data about visitors. Positive practice of study visits that had a direct effect on the preparation of the Festival and on the mobility of artists and professionals in the field of theater and drama is analyzed in depth and put in comparative perspective related to the Festival. Data on cooperation between the two countries in the field of theater and promotion of drama supported within budget of the Croatian Ministry of Culture during the Festival as well as in the period of three years before the Festival and three years after it were proven. According to the research approach, this is an intrinsic case study.

Keywords: cultural diplomacy, international cooperation, cultural policy, festival, mobility 


\section{Kazalište i dramski tekst na festivalu Croatie, la voici u Francuskoj}

Mobilnost je proces koji ne podrazumijeva samo fizičko kretanje, nego obuhvaća širi pojam prijenosa znanja, vještina, djela, roba i usluga. Ona se odnosi na proces, orijentirana je na rezultat i razmjenu, a ne samo na putovanje preko granica jedne države. Važnost mobilnosti potvrđena je i na razini Europske unije, uzevši u obzir činjenicu da je ona zasnovana na temeljima četiriju osnovnih tržišnih sloboda, od kojih se tri odnose na slobodu kretanja: roba, usluga i kapitala. Pritom, govoreći o području kulture na europskoj razini, bitno je istaknuti važnost mobilnosti za cirkulaciju kulturnih i kreativnih djela koju ističe Nova europska agenda za kulturu, koju je u svibnju 2018. godine donijela Europska komisija. U njoj se ističe važnost mobilnosti za poticanje, razvoj i održavanje suradnji među profesionalcima u kulturnom i kreativnom sektoru ${ }^{1}$. Poticanje mobilnosti, osim što olakšava fizičko kretanje umjetnika i profesionalaca izvan nacionalnih granica, potiče međukulturni dijalog i promicanje kulturnih razmjena. U ERICartsovoj studiji Mobility Matters iz 2008. godine stoji kako je mobilnost u kulturi korisna za stjecanje profesionalnog iskustva potrebnog za napredovanje u karijeri, za napredak u umjetničkom radu, te ju je potrebno uvesti kao sastavni dio redovnog radnog života umjetnika i drugih kulturnih djelatnika ${ }^{2}$. Na taj se način dižu profesionalni kapaciteti kulturnih djelatnika, otvaraju se nove mogućnosti umrežavanja, grade se dugoročna partnerstva i ostvaruju kontakti, dolazi se do novih publika i prilika u razvoju karijere. Imajući na umu te hipoteze, kroz ovaj istraživački rad je napravljena analiza aktivnosti koje su ostvarene u pripremi i provedbi dijela Festivala hrvatske kulture u Francuskoj vezanih uz programe koji su se odnosili na hrvatsko kazalište i dramsko pismo. Riječ je o Festivalu koji se odvio u Francuskoj 2012. godine, a kao posljedica državničkih odluka na razini predsjednika Hrvatske i Francuske, i time postaje jedan način primjene kulturne diplomacije.

Svrha je ovog rada propitati kako je ostvarena mobilnost u kulturi u pripremi i provedbi programa Festivala Hrvatske u Francuskoj u dijelu koji se odnosi na kazalište i dramsko pismo te utvrditi učinke tih napora koje povezuje transverzalni pojam kulturne diplomacije. Budući da rezultati koji proizlaze iz ovog istraživanja ne teže generalizaciji, ovaj rad se može

${ }^{1}$ https://ec.europa.eu/info/law/better-regulation/initiatives/ares-2018-1522768_en [pristup: 04.03.2019].

${ }^{2}$ Mobility Matters: Programmes and Schemes to Support the Mobility of Artists and Cultural Professionals, Final Report. European Institute for Comparative Cultural Research gGmbH, 2008, http://ec.europa.eu/assets/eac/culture/policy/cultural-creative-industries/ documents/mobility-matters-report_en.pdf [pristup: 17.04.2019]. 
identificirati kao intrinzična studija. Studije koje se smatraju intrinzičnima uglavnom služe sužavanju istraživačkih teorija $i$ „partikulariziranju“ analize (Lipset, Trow, Coleman, 1956: 419-420), a istraživač želi doprinijeti analizi specifičnog predmeta analize. Pri uporabi intrinzične studije slučaja „istraživač nije nužno zainteresiran za proučavanje ili stvaranje općih teorija ili generaliziranja“", stoga je u ovom radu uzet samo jedan segment Festivala hrvatske kulture u Francuskoj. Utvrđivanjem opisa sadržaja održanih programa, točnog broja uključenih organizacija u pripremu i provedbu tih programa, broja uključenih hrvatskih umjetnika i broj uključenih francuskih profesionalaca, broja izvedbi pojedinih programa i podataka o posjećenosti, pridonijelo se postizanju što cjelovitije slike o učincima koji su ostvareni ovim projektom u području mobilnosti. Dobiveni podaci stavljeni su u međuodnos kojim se nastoje utvrditi podaci koji govore o mobilnostima koje su ostvarene kroz različite slojeve obrađenih programa i o produbljivanju veza koje su nastale zahvaljujući Festivalu. Analizirani su podaci o suradnjama koje su podržane proračunom Ministarstva kulture i natječajima o Javnim potrebama u kulturi između Hrvatske i Francuske u području kazališta i poticanja dramskog pisma tijekom Festivala te tijekom tri godine prije održavanja Festivala i tri godine nakon njegove provedbe. Na taj je način procijenjeno je li došlo do povećanja broja kazališnih i dramskih programa između Hrvatske i Francuske i njihova sufinanciranja. Kako bi se osigurala što relevantnija provedba istraživanja, u prikupljanju podataka su upotrijebljeni različiti pristupi i metodologije prikupljanja podataka. Pritom se kod prikupljanja podataka i njihove analize vodilo računa o svim trima osnovnim načelima prikupljanja podataka koristeći se višestrukim izvorima, kreiranjem baze podataka i pažljivim održavanjem lanca dokaza (Yin, 2007: 116-126.). Budući da je riječ o kvalitativnom istraživanju, upotrijebljena je triangulacija podataka kao izvor provjere i potvrde informacija koje se postavljaju u međuodnose na kraju rada imajući u vidu da se „Triangulacija [...] provodi kako bi se povećala vjerodostojnost dokaza“"4. U prikupljanju podataka za analizu se vodilo računa o autentičnosti podataka, što se ocjenjivalo podjelom na primarne i sekundarne izvore. Na raspolaganju su bili sljedeći izvori podataka: službeni dokumenti u koje se uvrštavaju izvješća i dokumentacija u pohrani Francuskog instituta i hrvatskog Ministarstva kulture, arhivski zapisi, intervjui, medijski izvori, audio-vizualni zapisi, prijavni obrasci korisnika, izvješća korisnika nakon izvršenih programa i fizički artefakti u koje se uvrštavaju promotivni materijali i publikacije samog događanja,

${ }^{3}$ D.-R. Hancock, R. Algozzine: Doing Case Study Research: A Practical Guide for Beginning Researchers. New York, Teachers College Press, 2006, s. 32.

${ }^{4}$ R.E. STAKe: Qualitative research: Studyng How things work, strategies of qualitative inquiry. New York, The Guilford Press, 2010, s. 126. 
promotivni materijali čitavog Festivala i izvješća uključenih u rad Mješovitog organizacijskog odbora (CMO). Iz njih su crpljene osnovne informacije za istraživanje o pripremi i provedbi Festivala, dok su na raspolaganju bili korespondencija elektroničkom poštom i nesvrstani materijali kao sekundarni izvori. Održavanje lanca dokaza, koje Yin prikazuje kao jedno od triju načela koje „treba slijediti kako bi se povećala pouzdanost informacija u studiji slučaja" ${ }^{\prime \prime}$, osigurano je na način da je poštivan i tijekom cijelog istraživanja provjeravan međuodnos izvještaja, baze podataka, citata specifičnih dokaznih izvora u bazi, protokol i osnovna pitanja studije slučaja. Svaka iznesena informacija $u$ izvještaju studije provučena je kroz filter vjerodostojnosti, što je osigurano na način da je za svaki uvršteni iskaz u ovoj studiji propitana povezanost i relevantnost $\mathrm{u}$ odnosu na spomenute sastavnice lanca dokaza. Taj je proces izvršen tako da je pri skupljanju podataka u tabličnim shemama stavljena oznaka prihvatljivosti te, ako se dobiveni podatak nije poklapao sa svim navedenim uvjetima, taj se podatak nije uvrstio u izvještaj o studiji slučaja. Provedenom terenskom istraživanju prethodila je analiza konteksta unutar kojih je Festival hrvatske kulture u Francuskoj organiziran te na koji način se kulturna diplomacija kao koncept međunarodnih suradnji ostvaruje u Republici Hrvatskoj i Francuskoj Republici.

\section{Kulturna diplomacija u Francuskoj i Hrvatskoj}

Kulturna diplomacija kao uže promatrana smjernica međunarodne kulturne politike čini samo jednu sastavnicu vanjske politike i samim time jedno područje djelovanja diplomacije. Govoreći o razlici između vanjske politike i diplomacije, potrebno je naglasiti kako je vanjska politika „skup različitih pod-politika“6 dok je diplomacija, prema Guillaume Devinu, „skup dionika i metoda koji provode i oblikuju smjernice vanjske politike ${ }^{\prime \prime 7}$. Vanjska politika uređuje prirodu i orijentaciju odnosa koje jedna država želi provoditi s drugim zemljama, dok diplomacija uređuje njezinu provedbu u smislu dionika, instrumenata i procedura koji djeluju u području vanjske politike. Kulturnu diplomaciju treba promatrati kao instrument vanjskopolitičkog djelovanja, i ona prema Paul Painchaudu ${ }^{8}$ predstavlja najdinamičniji oblik međunarodne kulturne suradnje koja u suvremenim politikama sve

${ }^{5}$ R.K. YIn: Studija slučaja - dizajn i metode. Zagreb, Fakultet političkih znanosti, 2007, s. 124.

${ }^{6}$ M.-C. Kessler: La politique étrangère de la France. Acteur et processus. Paris 1999, s. 15.

7 G. Devin: Les diplomaties de la politique étrangère. U: Politiques étrangères. Nouveaux regards. Ur. F. Charillon. Paris, Presses de Sciences Po, 2002, s. 217.

${ }^{8}$ F. Chaubet: L'Alliance française ou la diplomatie de la langue (1883-1914). „Revue historique“ 2004, br. 4 (632), s. 763-785. 
više uzima maha, ali se ne može svesti na zajednički nazivnik u provedbi jer svaka država provodi vlastiti model.

Francuska kulturna politika ima dugu i bogatu tradiciju, o čemu svjedoči i njezin današnji ustroj, razvijenost i razgranatost. Od početka 20. stoljeća država postaje kreator i provoditelj intelektualnog širenja francuske kulture i jezika, kako to navodi Francois Chaubet ${ }^{9}$, te se kulturna diplomacija od samih začetaka francuske kulturne politike promatra kao integrirana i relevantna njezina sastavnica ${ }^{10}$. Godine 1979. Jacques Rigaud ${ }^{11}$ napravio je Izvješće ${ }^{12}$ koje mnogi izvori smatraju osnovnim dokumentom za daljnje pozicioniranje kulture i umjetnosti u međunarodnim odnosima (Lombard; Martel; Painchaud) i aktivne uloge državnog aparata u njihovu stvaranju. Rigaudovo je izvješće bilo podloga za izradu raznih akcijskih planova i dokumenata koji su uslijedili u 1980-ima, kako bi u konačnici 1988. godine došlo do osnivanja Secretariat d'Etat charge des Relations culturelles internationales et de la Francophonie ${ }^{13}$ pri Ministarstvu vanjskih poslova. Time je potvrđena još jednom čvrsta pozicija Quai d'Orsaya u kreiranju francuske kulturne diplomacije, ali i činjenica da su francuski jezik i kultura neodvojivi u njezinu kreiranju. Naime, Francuska je centralizirala svoje djelovanje u području kulturne diplomacije u nadležnost Ministarstva vanjskih poslova, o čemu se nalazi potvrda i u reformnim koracima koji su započeli 2008. godine ${ }^{14}$.

Hrvatska je diplomacija tijekom povijesti uvijek bila predominantno upravljana od strane visokih intelektualaca, erudita i filozofa, kao što to $\mathrm{u}$ radu Europski kontekst hrvatske kulture i diplomacije (povijesno-filozofski pristup) vrlo jasno svjedoči Ljerka Schiffler ${ }^{15}$ navodeći biografije brojnih emi-

${ }^{9}$ Ibidem.

10 A. Lombard: Politique culturelle internationale: Le modèle français face à la mondialisation. Arles 2003, s. 70.

${ }^{11}$ P. Painchaud: Fédéralisme et théories de politique étrangère. „Études internationales” 1974 , br. 1 (5), s. $25-44$.

12 J. Rigaud: Les relations culturelles extérieures: Rapport au ministre des Affaires étrangères. Paris 1980.

${ }^{13}$ Décret n88-734 du 31 mai 1988 relatif aux attributions du secrétaire d'état auprès du ministre d'état, ministre des affaires étrangères, chargé des relations culturelles internationales et de la francophonie https://www.legifrance.gouv.fr/affichTexte.do?cidText e=JORFTEXT000000501712\&dateTexte= [pristup: 03.04.2019].

${ }^{14}$ U izvješću Senata iz 2009. godine naznačeno je kako je „cilj reforme o međunarodnom djelovanju u području kulture [...] prijeći iz logike vladanja, u kojoj je zarobljena povijesnim nasljeđem, u logiku politike utjecaja oslanjajući se na francusku kulturu koja ne traži samo kako biti pokazana nego kako se obogatiti u kontaktu s drugim kulturama prilagođavajući se lokalnim kontekstima“.

${ }^{15}$ Lj. Schiffler: Europski kontekst hrvatske kulture i diplomacije (povijesno-filozofski pristup). U: Rad HAZU. Knj. 492. Razred za društvene znanosti 43, 2005, s. 235-239. 
nentnih hrvatskih diplomata kroz povijest. Iako je kultura oduvijek bila dio međunarodne politike i diplomacije (Tarle 2005: 149, prema: Skoko i Kovačić 2009: 38), to u hrvatskom kontekstu nikada nije do kraja dovoljno jasno artikulirano u smislu njezine uloge i značaja. Kulturna diplomacija kao područje diplomatskog djelovanja koje može imati vrlo široke horizontalne i vertikalne učinke u ostvarivanju međusobnog razumijevanja između dviju zemalja, motivirana je promocijom kulture, ali u skladu s vanjskopolitičkim i gospodarskim prioritetima pojedine zemlje. Međutim, hrvatska je kulturna diplomacija još uvijek u nastajanju. $\mathrm{O}$ tome svjedoče i razjedinjene i neusustavljene komunikacije među različitim tijelima državne uprave koja na posredan ili neposredan način provode neki oblik kulturne diplomacije. Zoran Pičuljan u knjizi Diplomacija kao državna služba navodi kako „Podjela nadležnosti između Ministarstva kulture, koje je odgovorno za programe međunarodne suradnje, i Ministarstva vanjskih poslova i europskih integracija, koje ima mrežu kulturnih atašea u svijetu, rješenje je koje do sada nije uvijek jamčilo sustavno vođenje međunarodne kulturne promidžbe ${ }^{\prime 16}$. Uzimajući u obzir svrhu kulturne diplomacije kako ju definira Lucian Jora da uspostavi povjerenje, a ne da služi kao demonstracija nacionalnih kulturnih dostignuća ${ }^{17}$, u ovom radu je analizirana suradnja koja se odvila kroz programe kazališnih i dramskih aktivnosti Festivala Hrvatske u Francuskoj 2012. godine.

\section{Festival Croatie, la voici u Francuskoj}

Kulturna sezona manifestacija je koja se održava od 1985. godine, a prilikom koje odabrana zemlja ima mogućnost predstaviti se francuskoj javnosti raznim programima u Parizu i drugim gradovima Francuske. Riječ je o manifestaciji koja proizlazi iz francuske vanjskopolitičke inicijative, koja Francusku direktnije i snažnije povezuje s pojedinom zemljom, a kroz prizmu kulture. Više je od pedeset zemalja do danas predstavljeno tim modelom kulturne diplomacije u Francuskoj, čime su dobile priliku intenzivirati razmjene i dobiti povećanu vidljivost kako u francuskim okvirima tako i na međunarodnoj razini. Radi se o značajnom događanju za pojedinu zemlju, koja tim povodom raznim sadržajima promovira svoju kulturu u najširem smislu riječi. Ona je prvenstveno zamišljena kao potvrda glavnih smjernica francuske kulturne politike koja se zasniva na raznolikosti i njegovanju di-

16 Z. PIČUlJAn: Diplomacija kao državna služba. Zagreb, Društveno veleučilište u Zagrebu, 2007, s. 15.

17 L. JoRA: New practices and trends in cultural diplomacy. U: Romanian Review of Political Sciences and International Relations 2013, sv. 10, br. 1. http://journal.ispri.ro/wp-content/ uploads/2013/03/43-52-Lucian-Jora.pdf [pristup: 05.10.2017]. 
jaloga. U tom smislu su ciljevi mehanizma kulturnih sezona jasno definirani i prepoznaju se kroz različite smjerove: vođenje aktivnosti koje su namijenjene jačanju međusobnog razumijevanja i upoznavanja; vrednovanje i/ili stvaranje novih preduvjeta za shvaćanje drugih kultura; isticanje važnosti razmjena u području kulture, obrazovanja, ali i tehnologije, znanosti, ekologije, gospodarstva i svih grana jedne ekonomije; iniciranje novih susreta i polja dijaloga ${ }^{18}$. Format kulturnih sezona može biti Festival kada je riječ o događanju u trajanju do 3 mjeseca, Sezona kada je riječ o trajanju od 3 do 6 mjeseci ili Godina kada je riječ o trajanju od 6 do 12 mjeseci ${ }^{19}$. Tijekom dogovorenog razdoblja u Francuskoj se predstavlja kultura pojedine zemlje, dok se ponekad dogovore i uzvratni događaji, kada se Francuska potom predstavi u toj istoj zemlji s kojom je započela suradnje ${ }^{20}$.

Ideja i potreba za održavanjem kulturne sezone dogovara se diplomatskim putem, a za njezinu organizaciju i provedbu zadužen je Mješoviti organizacijski odbor, koji je odgovoran za financijske i ljudske resurse prema programima i aktivnostima. Inicijativa za predstavljanje Hrvatske kroz mehanizam kulturnih sezona potakla je iz bilateralnih susreta hrvatskog predsjednika Stipe Mesića i francuskog Nicolasa Sarkozya te se potom potvrdila Akcijskim planom hrvatsko-francusko strateškog partnerstva koji su potpisali hrvatska premijerka Jadranka Kosor i francuski premijer François Fillon 9. srpnja 2010. godine, Tehničkim sporazumom o načelima organizacije i financiranja Festivala hrvatske kulture u Francuskoj ${ }^{21}$, koji je potpisan u Zagrebu 18. listopada 2011. godine između Nine Obuljen, državne tajnice u hrvatskom Ministarstvu kulture, i Sylviane Tarsot-Gillery ${ }^{22}$, glavne ovlaštene ravnateljice Francuskog instituta, te je provedba Festivala, službenog naziva Croatie, la voici, povjerena sljedećim predstavnicima: za hrvatsku stranu Ministarstvu kulture Republike Hrvatske, a za francusku stranu Francuskom institutu, predstavniku Ministarstva vanjskih i europskih poslova za područje francuskog inozemnog kulturnog djelovanja. Priprema i provedba festivala Croatie, la voici potvrda je kako kulturna diplomacija može značiti instrumentalizaciju kulture koju diplomacija vrši provedbom svoje vanjske politike kao

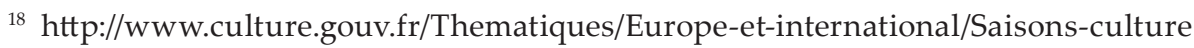
lles [pristup: 05.04.2019].

19 https://www.pro.institutfrancais.com/fr/offre/saisons-et-annees-croisees [pristup: 05.04.2019].

${ }^{20}$ Nastavak Festivala hrvatske kulture u Francuskoj 2012. godine bio je Festival Rendez-vous u Hrvatskoj, kada se Francuska predstavljala kroz uzvratnu sezonu.

${ }^{21}$ Naznačeno u 2. poglavlju Tehničkog sporazuma, koji je pohranjen u arhivima Ministarstva kulture Republike Hrvatske.

22 Jean-François Guéganno, ravnatelj za razvoj i partnerstva iz Francuskog instituta, predstavljao je Sylviane Tarsot-Gillery, glavnu ovlaštenu ravnateljicu Francuskog instituta te $\mathrm{u}$ njezino ime potpisao dokumente. 
„aktivnost koju uspostavlja država kako bi definirala svoje odnose s vladama drugih država [...] i dala naglasak na postojanje srži političke volje i provođenja u administrativnom smislu" (Kessler, 1999: 169). Pritom je čitav festival zasnovan na načelima mobilnosti unutar kreativnog sektora, jer se „Kulturna diplomacija [...] najbolje može opisati kao slijed akcija koje se oslanjaju na razmjenu ideja, vrijednosti, tradicija i drugih aspekata kulture ili identiteta, bilo da je riječ o jačanju odnosa, jačanju socio-kulturne suradnje, promoviranju nacionalnih interesa i šire ${ }^{\text {233. }}$.

\section{Kazalište i dramski tekst u sklopu festivala Croatie, la voici u Francuskoj}

Prema Tehničkom sporazumu, glavne povjerenice ${ }^{24}$ imale su zadatak brinuti o konzistentnosti programa te su imale odgovornost za sastavljanje programa i traženje partnera u pripremi Festivala. Uz glavne povjerenice, o programima su brinuli i članovi Odbora. U Mješovitom organizacijskom odboru sudjelovali su predstavnici različitih resora te su oni koordinirali pripremu i odabir programa koji su se kasnije uvrstili u Festival. U tom smislu, članovi Mješovitog organizacijskog odbora bili su podijeljeni prema područjima te su imali dodijeljene uloge i odgovornosti shodno toj podjeli. $S$ hrvatske je strane za područje kazališta i dramskog pisma bila odgovorna jedna osoba, dok su s francuske strane bile uključene dvije osobe, jedna za područje kazališta, a druga za područje dramskog pisma. Moguće je zaključiti kako je tijekom jednogodišnje intenzivne pripreme Festivala te tijekom tri mjeseca njegove provedbe, ukupno pet osoba u državnoj administraciji bilo posvećeno transferu informacija, znanja i iskustava vezanih uz hrvatsko kazalište i dramsko pismo. Uz državne službenike, odnosno članove Mješovitog organizacijskog odbora, kao potpora organizaciji programa i poticanju daljnjih komunikacija među hrvatskim i francuskim sektorom, uključene su bile još dvije osobe iz organizacije $\mathrm{ONDA}^{25}$, kao potporne institucije za područje izvedbene umjetnosti u Francuskoj. Sve komunikacije koje su se ostvarivale između spomenutih dionika u konačnici su rezultirale sadržajem

${ }^{23}$ Internetske stranice Institute for Cultural Diplomacy, dostupno na: http://www. culturaldiplomacy.org/index.php?en_culturaldiplomacy [pristup: 15.04.2019].

${ }^{24}$ Za glavne povjerenice Festivala imenovane su: s hrvatske strane Seadeta Midžić, $\mathrm{s}$ francuske strane Isabelle Delage.

${ }^{25}$ ONDA predstavlja skraćenicu za Office national de diffusion artistique (Francuski ured za suvremenu izvedbenu umjetnost i cirkulaciju djela). Riječ je neprofitnoj javnoj organizaciji, Onda - Office (Francuski ured za cirkulaciju suvremene izvedbene umjetnosti), koja je osnovana 1975. godine. 
koji je tijekom Festivala ponudio francuskoj publici ukupno 15 programa vezanih uz kazalište i dramsko pismo. U nastavku rada navedene su osnovne informacije svakog pojedinog programa vezanog uz kazalište i dramsko pismo, kako bi se osigurao kontekst i uvid u sadržaj tih događanja. Kako bi se propitalo na koji način je provedena mobilnost djela, umjetnika i profesionalaca unutar kulturnog sektora, ključna pitanja na koja je tražen odgovor vezana su uz pitanje francuskih i hrvatskih organizacija koje su sudjelovale u pripremi i provedbi, imena i broj hrvatskih umjetnika i profesionalaca koji su sudjelovali u programima, broj izvedbi svakog pojedinog programa te posjećenost programa. Na taj je način moguće napraviti sintezu postignutog $\mathrm{u}$ području mobilnosti prema trima njezinim sastavnicama: mobilnost djela, mobilnost umjetnika i mobilnost znanja koja je ostvarena programima tijekom Festivala. Podaci su objedinjeni, prikupljani prema metodologiji koja je ranije opisana te su na kraju rada izvedeni zaključci iz dobivenih informacija.

U suradnji s kazalištem Comédie Française organiziran je Ciklus od triju večeri čitanja hrvatskih dramatičara u kazališnoj dvorani Studio-Théâtre, koji je treća i ujedno najmanja scena kazališta Comédie Française, osnovana 1996. godine za potrebe manjih predstava, prezentacija i događanja. Odabrana su tri dramska djela koja su programirana za program javnog čitanja u dvorani Studio-Théâtre kao dio redovnog programa, kojima su predstavljena tri različita razdoblja hrvatske književnosti. Čitanje dramskog djela Dundo Maroje Marina Držića režirao je Nicolas Lormeau, čitanje dramskog djela Gospoda Glembajevi Miroslava Krleže režirao je Laurent Muhleisen i čitanje dramskog teksta Europa - monolog za majku Courage i njezinu djecu Ivane Sajko režirao je Nâzim Boudjenah. Djela su čitali glumci kazališta, dok je na čitanju svoje drame književnica Ivana Sajko bila prisutna. Prema izvješću kazališta Comédie Française koje je arhivirano u Francuskom institutu, bilo je ukupno 280 gledatelja u tri dana. S hrvatske strane je partner bilo Hrvatsko društvo pisaca, ali samo u funkciji operativne podrške, bez sugestija u sadržaj, te je za izbor i izvedbu djela odgovorno kazalište Comédie Française.

U prostoru biblioteke Centra Pompidou ${ }^{26}$ održao se program naziva „Les Rêves (dés) enchantés de la Croatie", i to samo jednu večer. Koncept je događanja bio okrugli stol na temu „Hrvatska, pozornica Europe“, a koji je moderirala Anne Madelain. Kao gosti su sudjelovali Daša Drndić, Srećko Horvat, Igor Štiks i Ivana Sajko te Jacques Rupnik ${ }^{27}$. S hrvatske strane partner je bilo Hrvatsko društvo pisaca, ali samo u funkciji operativne podrške, bez sugestija u sadržaj, koji su koncepcijski osmislile Emmanuèle Payen, programatorica iz biblioteke Centre Pompidou, i Anne Madelain, znanstvenica

\footnotetext{
${ }^{26}$ Franc. Bibliothèque Publique d'Information (BPI).

27 Politolog u Centre de recherches internationales (CERI).
} 
zadužena za međunarodne suradnje u EHESS ${ }^{28}$. Prema izvješću biblioteke Centre Pompidou koje je arhivirano u Francuskom institutu, bilo je ukupno 120 gledatelja.

Festival d'Automne u Parizu, međunarodni je festival suvremene umjetnosti, koji od rujna do prosinca svake godine privlači više od 100 tisuća posjetitelja programirajući različite umjetničke discipline. Koncept je Festivala upoznati francusku javnost $\mathrm{s}$ djelima visoke umjetničke vrijednosti, često ugošćujući autore koji su skloni eksperimentu. Umjetnička direktorica Marie Collin odabrala je za gostovanje u sklopu Festivala d'Automne predstavu $S$ druge strane Zagrebačkog kazališta mladih koju potpisuje hrvatski autorski dvojac Bobo Jelčić i Nataša Rajković, a u predstavi glume Nikša Butijer, Jadranka Đokić, Ksenija Marinković i Krešimir Mikić. Riječ je o predstavi koja se bavi životima četvero usamljenih ljudi i njihovim naporom da nam ispričaju svoje priče. $S$ hrvatske strane partnerska institucija je bilo Zagrebačko kazalište mladih, a s francuske strane Festival d'Automne i kazalište La Colline. Predstava je odigrana u kazalištu La Colline sedam puta. Predstavu je u tih par večeri ukupno pogledao 2041 gledatelj.

Predstava Forecasting autorskog dvojca Barbare Matijević i Giuseppea Chica, uz dramaturšku podršku Saše Božića, nastala je u produkciji Kaaitheater iz Bruxellesa i koprodukciju Uovo iz Milana. Kao dio Festivala hrvatske kulture u Francuskoj je prikazana četiri puta u Menagerie de verre u sklopu Festivala d'Automne. Riječ je o predstavi koja čini dio trilogije započete radom I am 1984., a temelji se na zbirci amaterskih videa preuzetih s najpopularnijeg internetskog servisa za razmjenu videosadržaja - YouTubea. Na pozornici, izvođačica Barbara Matijević manipulira prijenosnim računalom na čijem se zaslonu nižu videouradci s YouTubea, od kojih svi poštuju mjerilo 1:1, odnosno odgovaraju realnim veličinama osoba i predmeta. S hrvatske strane je tehničku potporu dala umjetnička organizacija De facto, a s francuske strane Festival d'Automne. Predstava je izvedena četiri večeri, a prema izvješću pohranjenom u Francuskom institutu pogledalo ju je 388 gledatelja.

Predstava Car neuspjeha Zagrebačkog kazališta mladih, prema tekstu i u režiji Jana Fabrea, pozvana je u Théâtre de Gennevilliers gdje je odigrana u dvama terminima. Riječ je o monodrami u kojoj glumi hrvatski glumac Frano Mašković. S hrvatske strane je u organizaciju i prikazivanje predstave uključeno Zagrebačko kazalište mladih, dok je s francuske strane izbor i provedbu osiguralo kazalište iz Gennervilliersa. Prema podacima dostupnim u arhivima Francuskog instituta u izvješćima korisnika, nije zabilježen točan podatak o broju posjećenosti.

Profesionalna kazališna družina Triko koja posebno njeguje izričaj teatra novog cirkusa gostovala je s predstavom Slavuj u Salle des Fêtes de Garge-

${ }^{28}$ Franc. Éditions de l'école des hautes études en sciences sociales (EHESS). 
nville. Program je ostvaren kao rezultat suradnje s francuskom redateljicom Lee Delong. Riječ je o cjelovečernjoj klaunskoj predstavi za odrasle u kojoj nastupaju četiri glumca plesača i glazbeni trio, a koja se bazira na tehnikama klaunovskog kazališta škole Jacquesa Lecoqa. Nastala je u koprodukciji Triko cirkus teatra s Kulturom promjene Studentskog centra i Međunarodnim centrom za usluge u kulturi. Uz četiri hrvatska umjetnika koji izvode scenski nastup: Nikolina Majdak, Domagoj Šoić, Nikola Mijatović i Iva Peter-Dragan, nastupila su tri glazbenika: Davorka Horvat, Frederic Lang i Nicolas Sinković. S hrvatske strane partnerska institucija bila je kazališna družina Triko, a s francuske strane kazalište Gargenville. Režiju i dramaturgiju potpisuje francuska redateljica Lee Delong. Predstava je izvedena jednom te ju je pogledalo 215 gledatelja.

Kratki komad „Vane“ napisao je Radovan Ivšić za teatar sjena 1943. godine. Predstavu je prema predlošku Radovana Ivšića koncipirao i interpretirao Clément Peretjatko te je nastala u koprodukciji Théâtre du Hangar, Centre d'art et de recherche, Cie Jacques Bioulès i kazališne družine Collapse. Tijekom Festivala Hrvatske u Francuskoj, predstava Vane u režiji Clementa Peretjatka izvedena je u četirima različitim prostorima: u kazalištu Mains Nues, knjižnicama Marguerite Audoux i Buffon te na Sveučilištu Paris-Sorbonne. $S$ hrvatske strane nije bilo partnerske institucije dok je $s$ francuske strane produkciju osigurala Compagnie Collapse. Predstava je prikazana šest puta na različitim lokacijama, a prema izvješću korisnika u arhiviranim podacima Francuskog instituta zabilježeno je kako ju je vidjelo ukupno 160 gledatelja.

Festival Est-Ouest svake godine posveti svoje izdanje jednoj gostujućoj zemlji, te su tako 2012. godine stavili Hrvatsku u fokus. U sklopu desetodnevnog događanja u gradu Die i okolici održano je više od trideset različitih događanja koja su uključivala različita kulturna događanja: prikazivanja filmova, predstave, okrugle stolove, predstavljanje knjiga i izložbe. U članku Drage Roksandića "Croatie, la voici“, 22. festival Est-Ouest, Die (departman Drôme), 19.-30. rujna 2012., posvećen Hrvatskoj piše: „Za mene su mnogo zanimljivije iskustvo bili ljudi koji se tko zna čime sve bave u životu, ali koji su imali potrebu obogatiti svoje uvide i znanja o jednoj zemlji, Hrvatskoj, njezinim ljudima, njihovu radu i stvaralaštvu na način koji je bio sve prije nego kurtoazan $^{\prime 29}$. U kazališnom dijelu Festivala Est-Ouest u suradnji s Théâtre Ô, šest francuskih i pet hrvatskih glumaca izvelo je djelo Radovana Ivšića Sunčani grad u režiji Marca Sollogouba, uz prisustvo Luke Barešića, Dalije Dozet, Ivane Krizmanić, Sanje Milardović, Dinke Vuković i Antonija Franića. Djelo je izvedeno u Kazalištu Die, a prije same predstave gledateljima

29 D. Roksandić: „Croatie, la voici“, 22. festival Est-Ouest, Die (departman Drôme), 19.-30. rujna 2012., posvećen Hrvatskoj. „Radovi - Zavod za hrvatsku povijest“ 2013, br. 1 (45), s. $265-278$. 
je predstavljen rezultat dramskih radionica koje su prethodile izvedbi i bile otvorene za sve zainteresirane. Naime, tijekom tjedan dana Marc Sollogoub sa zainteresiranima je radio na izvedbi raznih tekstova, među kojima i tekstovima Radovana Ivšića i Annie Lebrun (uz tekstove autora: Dante, Arthur Rimbaud, André Breton, Benjamin Péret, Pier Paolo Pasolini i Boris Zaïtsef). Rezultat je tog jednotjednog rada bio prikazan dva puta na dan početka Festivala Est-Ouest. Nakon odigrane predstave, $\mathrm{u}$ istom je kazalištu organizirana diskusija pod nazivom „Susret s Radovanom Ivšićem” kojem su uz umjetničku ekipu predstave sudjelovali Daniel Barić, Bernard Lory i Annie Lebrun. S hrvatske strane nije bilo partnerske institucije dok je s francuske strane produkciju osiguralo kazalište Théâtre Ô. Predstava je prikazana jednom, a prema izvješću korisnika u arhiviranim podacima Francuskog instituta, zabilježeno je kako ju je vidjelo ukupno 153 gledatelja.

Predstava Mrzim istinu izvedena je u Kazalištu Die. Riječ je o predstavi čiji tekst i režiju potpisuje Oliver Frljić, a glume Ivana Roščić, Rakan Rushaidat, Filip Križan i Iva Visković. Zbog specifične scenografije, gdje je publika smještena oko prostora za dramsku igru, nisu bili osigurani titlovi koji prate predstavu. Publika je imala prilike prije same izvedbe dobiti tekst te je prije samog početka izvedbe prisutnima na francuskom jeziku dan kontekst i uvod u samo djelo, što je učinio umjetnički direktor Festivala Harold David. Nakon izvedene predstave, upriličen je razgovor publike s redateljem predstave Oliverom Frljićem. S hrvatske je strane partnerska institucija bilo kazalište ITD, a s francuske strane Udruga Festival Est-Ouest i Kazalište Die. Predstava je prikazana jednom, a prema izvješću korisnika u arhiviranim podacima Francuskog instituta, zabilježeno je kako ju je vidjelo ukupno 56 gledatelja.

Mon petit guide en Croatie kazališna je izvedba koja se odvija tijekom vožnje autobusom, u sklopu Festivala Est-Ouest. Jedan od triju autora teksta, hrvatski umjetnik Darko Japelj gledatelje pretvara u turiste koje provodi kroz hrvatske pejzaže i kontekst te im se na putu događaju razne situacije. Od četiriju izvedbi koje su ostvarene, uz usputna stajanja tijekom izvedbe, dvije su predstave uključivale degustacije u podrumu Die-Jaillance, a dvije u podrumu Carod te posjet lokalnom Muzeju Clairette de Die. S hrvatske strane nije bilo partnerske institucije, a s francuske strane su to bile Udruga Festival Est-Ouest i Kazalište Die. Prema izvješću korisnika u arhiviranim podacima Francuskog instituta, zabilježeno je kako je u četirima izvedbama sudjelovalo 75 gledatelja.

U sklopu Festivala Est-Ouest organiziran je okrugli stol na temu suvremenog hrvatskog dramskog pisma. U diskusiji su sudjelovali Oliver Frljić, Ivana Sajko i Slobodan Šnajder, dok je događanje moderirao Miloš Lazin, redatelj srpskog porijekla. S hrvatske strane je partnerska institucija bilo Hrvatskog društvo pisaca, a s francuske strane Udruga Festival Est-Ouest. 
U svim pretraženim materijalima i proučavanim arhivskim dokumentima nije pronađen podatak o točnom broju publike.

U sklopu Festivala Est-Ouest organiziran je susret s Predragom Lucićem i Ivanom Sajko, s ciljem predstavljanja njihova djelovanja i rada. S hrvatske strane je partnerska institucija bilo Hrvatskog društvo pisaca, a s francuske strane Udruga Festival Est-Ouest. U svim pretraženim materijalima i proučavanim arhivskim dokumentima nije pronađen podatak o točnom broju publike.

U sklopu kazališnog programa Festivala Est-Ouest, u kazalištu Die je organizirano čitanje dramskog djela Peto evanđelje Slobodana Šnajdera. U predstavljanju je sudjelovalo sedam francuskih umjetnika u režiji Miloša Lazina, redatelja iz Srbije. Nakon čitanja je organiziran susret s autorom Slobodanom Šnajderom. S hrvatske strane je partnerska institucija bilo Hrvatskog društvo pisaca, a s francuske strane Udruga Festival Est-Ouest i kazalište Die. U svim pretraženim materijalima i proučavanim arhivskim dokumentima nije pronađen podatak o točnom broju publike.

U sklopu kazališnog programa Festivala Est-Ouest, u vanjskom prostoru festivala organizirano je javno čitanje tekstova iz Antologije suvremenog hrvatskog dramskog pisma, iz 2012. godine u izdanju nakladničke kuće L’Espace d'un instant, a koju je uredila Nataša Govedić u suradnji s Dominique DoImieu i Milošem Lazinom. Za ovu priliku čitani su ulomci iz sljedećih tekstova: Predstava Hamleta u selu Mrduša Donja Ive Brešana, Veliki bijeli zec Ivana Vidića, Svećenikova djeca Mate Matišića, Enciklopedija izgubljenog vremena Slobodana Šnajdera, Diši Asje Srnec Todorović i Rose is a rose is a rose... Ivane Sajko. $S$ hrvatske strane nije bilo partnerske institucije, a s francuske strane su to bile Udruga Festival Est-Ouest i kazalište Die. U svim pretraženim materijalima i proučavanim arhivskim dokumentima nije pronađen podatak o točnom broju publike.

Kompanija Room 100 izvela je predstavu C8H11NO2 u kazalištu Die, u izvedbi i režiji umjetnika Jakova Labrovića. Riječ je o predstavi suvremenog cirkusa koja tematski obrađuje temu shizofrenije, "ali je režirana ne isključivo kao opisivanje psihičke bolesti na sceni već kao prikaz širokog dijapazona emocija kroz koje prolaze ljudi pomaknutog stanja svijesti i fizičke reakcije osoba izrazito bliskih oboljelima". S hrvatske je strane partnerska institucija bilo Hrvatskog društvo pisaca, a s francuske strane Udruga Festival Est-Ouest i kazalište Die. Zabilježeno je 209 gledatelja na predstavi.

Prema napravljenim analizama može se ustanoviti kako je ukupno održano 15 programa vezanih uz kazalište i dramsko pismo, od kojih devet predstava i šest programa vezanih uz dramsko pismo. Ukupno je riječ o 35 izvedbi, pri čemu se njih 27 odnosi na kazališne predstave, a njih 8 na događanja povezana s dramskim pismom općenito. Tijekom Festivala je nastupilo 37 umjetnika, od čega njih 28 u kazališnim predstavama, a 9 u programima 
vezanim uz dramsko pismo. Od ukupno 27 kazališnih izvedbi, vezano uz posjećenost događanja, dostupni su podaci za njih 26 te je izračunato kako ih je pogledalo ukupno 3188 gledatelja. Od šest događanja vezanih uz dramsko pismo, četiri programa je posjetilo 423 osobe dok za dva nisu dostupni podaci. Može se zaključiti kako je programe popratilo više od 3500 ljudi osobno na licu mjesta. Analizom prethodno navedene dokumentacije ustanovljeno je kako je u organizaciji i provedbi kazališnih i dramskih programa festivala Croatie, la voici sudjelovalo deset francuskih kulturnih institucija i organizacija: Comédie française, Festival d'Automne, Compagnie Collapse, Festival d'Automne, Festival d'automne, Théâtre Gargenville, Centre Pompidou, le Théâtre Ô, Udruga Festival Est-Ouest i Kazalište Die. S hrvatske strane je sudjelovalo pet hrvatskih institucija: Hrvatsko društvo pisaca, Zagrebačko kazalište mladih, umjetnička organizacija De facto, kazališna družina Triko cirkus i Studentski centar.

Za potrebe ovog rada provedeno je istraživanje putem upitnika online $\mathrm{u}$ formi strukturiranog intervjua s ciljem ispitivanja rezultata provedenih mobilnosti. Ispitivanje je napravljeno metodama strukturiranog intervjua jer je za kvalitativne ispitivače riječ o metodologiji kojom najčešće dolaze do informacija od većeg broja ljudi o pitanju ili temi do koje sam istraživač nema pristup odgovoru (Stake, 2010: 95) ${ }^{30}$. Upitnik je bio namijenjen osobama koje su bile aktivno uključene u pripremu i provedbu festivala Croatie, la voici 2012. godine jer je njegov cilj bio dobiti ocjenu i informacije s terena o konkretnim iskustvima uključenih te je poslan na adrese svakog uključenog partnera s francuske i hrvatske strane koji su sudjelovali u pripremi i provedbi pojedinih programa. Ovaj je dio istraživanja u potpunosti bio anoniman te su podaci pohranjeni anonimno u bazi podataka istraživača. Ispitanicima je poslana i izjava o obavezi na tajnost i zaštiti individualnih podataka. Procjena je bila da je za ispunjavanje upitnika bilo potrebno deset minuta te su sudionici zamoljeni da ispune obrazac unutar deset dana. Nakon isteka sedam dana, poslana je na sve adrese zahvala uz molbu za ispunjavanjem onima koji nisu to do tada stigli učiniti. Za provođenje upitnika upotrijebljen je alat "Google obrasci“, u koji su unesena pitanja u formi strukturiranog intervjua dok su prikupljeni odgovori analizirani odmah po primitku. U prvih pet pitanja ispitanici su upoznati s obavezom anonimnosti i povjerljivosti podataka te su dali svoju suglasnost o sudjelovanju $u$ istraživanju. Od ukupno petnaest adresa na koje je poslan upitnik, prikupljeni su odgovori na njih četiri. Od toga dva s francuske strane i dva s hrvatske. Zbog slabog odaziva na ponuđeni upitnik, dobiveni rezultati nisu dostatni za relevantnu analizu cjeline, te su poslužili isključivo za potrebe kvalitativne analize pristiglih

${ }^{30}$ R.E. Stake: Qualitative research: Studying How things work, strategies of qualitative inquiry. New York, The Guilford Press, 2010, s. 126. 
odgovora. Ipak, slijedom provedenog ispitivanja, istraživanje je obogaćeno za dodatnu dimenziju koja doprinosi istraživanju o pitanju doprinosa provedenih aktivnosti tijekom pripreme i provedbe Festivala, a na temu mobilnosti u kulturnom sektoru i njezine posljedice provedbe kulturne sezone kao mehanizma kulturne diplomacije. Naime, na skupinu pitanja vezanih uz činjenicu da su programi ostvareni u okviru festivala Croatie, la voici svi pristigli odgovori su bili pozitivnog karaktera, te su korisnici naznačili kako do provedene suradnje ne bi došlo da nije bilo inicijative Festivala, odnosno konkretno navedenih aktivnosti koje su se odvile u sklopu „studijskih posjeta“ i "komunikacija s hrvatskim Ministarstvom kulture, organizacije ONDA iz Pariza i Francuskog instituta“. Stoga su u nastavku istraživanja objedinjene, sistematizirane i potom komparativno analizirane informacije vezane upravo uz aktivnosti studijskih posjeta, jer je riječ o pojavnosti koja je istaknuta kao poticaj za mobilnost u području kulture.

\section{Studijski posjeti tijekom pripreme festivala Croatie, la voici u Francuskoj}

S ciljem upoznavanja hrvatskog konteksta, tijekom jednogodišnjeg razdoblja priprema festivala Croatie, la voici u Francuskoj organizirani su studijski posjeti predstavnika francuskih kulturnih institucija i medija u Hrvatsku. Studijski posjeti i njihovo financiranje određeni su Tehničkim sporazumom o načelima organizacije i financiranja Festivala hrvatske kulture u Francuskoj, gdje je u poglavlju IV - Načela financiranja naznačeno kako će pripremne misije hrvatskih stručnjaka i predstavnika u Francuskoj biti na trošak hrvatske strane, a „misije traženja u Hrvatskoj stručnjaka i predstavnika francuskih prihvatnih struktura bit će na trošak francuske strane ${ }^{\prime / 31}$. Studijski posjeti bili su koncipirani zajedničkim usuglašavanjem dviju strana. Od travnja 2011. godine do listopada 2012. godine ukupno su organizirana 47 studijska posjeta tijekom kojih je Hrvatsku posjetilo 86 pojedinaca. Dva su osnovna koncepta organiziranih studijskih posjeta: grupni studijski posjet i pojedinačni studijski posjet. Kod grupnih studijskih posjeta organiziran je format Showcase za područje kazališta i plesa, dok su pojedinačni posjeti bili krojeni za svakog zasebno, ili za manju grupu poput slučaja kada su bila dva predstavnika za Festival u gradu Die. Program i sadržaj studijskih posjeta bio je koncipiran na način da bi s francuske strane pristigao interes prema

${ }^{31}$ Tehnički sporazum o načelima organizacije i financiranja Festivala hrvatske kulture u Francuskoj; Dokument se nalazi u Arhivima Ministarstva kulture Republike Hrvatske; Predmet spisa: Saison culturelle u Parizu 2012. (Klasa: 910-01/11-01/0017; Ur. broj: nije upisan), s. 2. 
određenim temama, umjetnicima ili specifičnostima kulture, na koje je hrvatska strana odgovarala prijedlozima i organizacijom posjeta. Francuskim profesionalcima bi potom bili osigurani podaci o razrađenom programu s detaljnim informacijama o svim sudionicima i potencijalnim partnerima s kojima će se susresti tijekom svoje studijske posjete.

\section{Studijski posjeti za područje kazališta i dramskog pisma}

Tijekom jednogodišnjih priprema Festivala organizirano je ukupno šest studijskih posjeta koji su imali za cilj upoznavanje francuskih profesionalaca s područjem kazališta i dramskog pisma u Hrvatskoj. Osim velike grupne studijske posjete vezane uz kazalište i dramsko pismo u formi Showcasea, organizirani su ciljani studijski posjeti za predstavnike Festivala Est-Ouest, Festivala D'Automne, kazališta D'Ivry i Gennevilliers te predstavnike potpornih institucija: Francuskog instituta i organizacije ONDA. Ukupno je riječ o pet pojedinačnih studijskih posjeta, koje su bile organizirane i posebno osmišljene prema prijedlozima i interesima francuskih gostiju koje su koordinatori iz festivalskog tima s povjerenicama Festivala nadogradili, a službe hrvatskog Ministarstva kulture i Francuskog instituta koordinirali. Tri pojedinca posjetila su Hrvatsku u dva navrata i sudjelovala u različitim studijskim posjetima: predstavnik organizacije ONDA, Francuskog instituta i Festivala Est-Ouest. Na Slici 1 ilustriran je broj profesionalaca koji su posjetili Hrvatsku po svakom pojedinom studijskom posjetu, te njihova uloga u kasnijoj provedbi festivala Croatie, la voici.

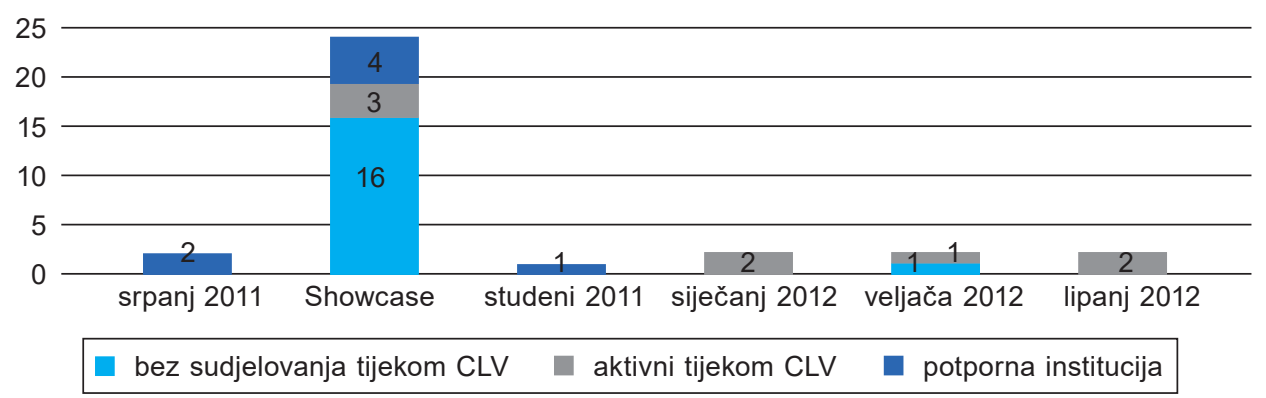

Slika 1: Sudionici studijskih posjeta

Na poziv Ministarstva kulture Republike Hrvatske, Hrvatski centar ITI organizirao je predstavljanje hrvatskih kazališnih predstava pod nazivom Hrvatski kazališni showcase od 18. do 22. listopada 2011. godine. Riječ je bila o sedmom izdanju Showcasea za koji je u Finalnom izvješću korisnika navedeno „osim uobičajenog poziva stranim producentima, selektorima, prevoditeljima i kazališnim kritičarima, imali smo čast i obvezu organiziranja 
Showcasea za Ministarstvo kulture Republike Hrvatske koje s francuskim partnerima radi kulturnu sezonu (Saison Croate) 2012. u Francuskoj gdje će se predstaviti najbolji primjeri cjelokupne hrvatske kulture pa tako i kazališne ${ }^{\prime \prime 32}$. U organizaciji Hrvatskog centra ITI predstave su pratila ukupno 23 profesionalca, od kojih 10 iz Francuske ${ }^{33}$. Budući da se od 20. do 29. listopada 2011. godine održavao međunarodni festival Perforacije - tjedan izvedbenih umjetnosti, još 13 francuskih profesionalaca koji su bili na tom događanju pratili su sadržaje i predstave 7. hrvatskog kazališnog showcasea. Prema izvješću Francuskog instituta, ukupno su 23 francuska profesionalca iz područja kazališta i izvedbenih umjetnosti bila u studijskom posjetu u Hrvatskoj od 19. do 22. listopada 2011. godine. Tijekom pet dana, francuski profesionalci su imali prilike pogledati 12 različitih predstava, u kojima su nastupila 142 hrvatska umjetnika. Uz prikazivanje predstava, bila su organizirana dva događanja $\mathrm{u}$ formatu druženja profesionalaca, jedno u organizaciji Centra ITI, a jedno u sklopu festivala Perforacije, na kojima su omogućene prilike za neformalno upoznavanje i umrežavanje francuskih gostiju s hrvatskim profesionalcima i glumcima. U tim prilikama, francuskim su profesionalcima bile na raspolaganju informativne brošure, prospekte, časopise, knjige i dramska djela koja su mogli uzeti na uvid ili trajni posjed.

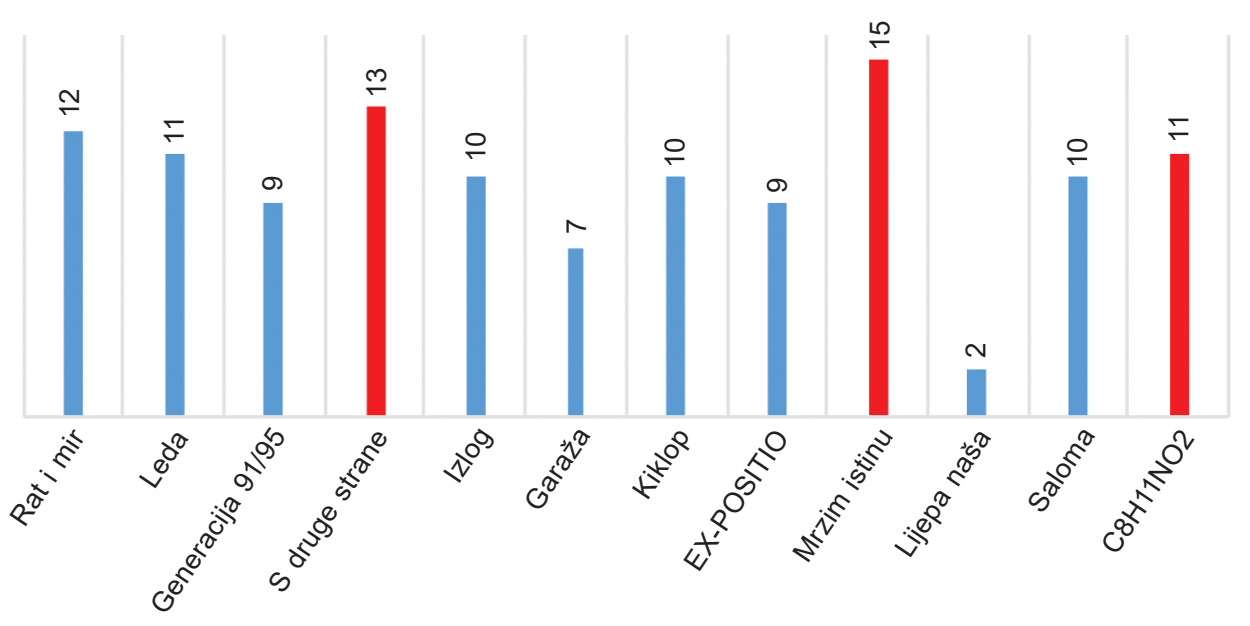

Slika 2: Prikaz prisutnih francuskih profesionalaca na pojedinoj predstavi tijekom Showcasea

32 Arhivi Ministarstva kulture Republike Hrvatske; Predmet: 7. hrvatski kazališni showcase (Klasa: 910-01/11-02/0228, 380-12-3).

${ }^{33} \mathrm{U}$ pratnji francuskih kazališnih profesionalaca bili su francuska povjerenica Festivala Hrvatske u Francuskoj Isabelle Delage i savjetnik za kazalište i glazbu iz Francuskog instituta u Parizu Louis Presset. 
U izvještaju predstavnika Francuskog instituta Louisa Presseta naznačeno je kako je „posjet francuskih profesionalaca [...] bio veliki uspjeh. Rijetkost je imati priliku vidjeti toliko gust raspored izvedenih predstava u normalnim uvjetima (pred publikom), s tolikom raznolikošću i s tolikim brojem profesionalaca koji se imaju prilike upoznati unutar par dana“34 te on navodi afinitete koje su pojedini francuski programatori i direktori kazališta pokazali za predstavljena djela. Od predloženih predstava koje su tijekom studijskog posjeta mogli pogledati, u sklopu festivala Croatie, la voici u Francuskoj su gostovale tri predstave: predstave Mrzim istinu i C8H11NO2 kao dio programa Festivala Est-Ouest te predstava $S$ druge strane koja je odigrana u kazalištu La Colline u Parizu. Moguće je izvesti zaključak kako je riječ o predstavama koje su pobudile najveći interes francuskih profesionalaca jer je prema podacima o posjećenosti predstava od strane francuskih profesionalaca vidljivo kako je riječ upravo o predstavama koje je pogledao najveći broj profesionalaca, što je vidljivo u prikazu na Slici 2.

Osim predstava koje su odigrane tijekom Festivala, kao izravna posljedica studijskih posjeta, ostvareno je dodatnih 4 programa u sklopu festivala Croatie, la voici u Francuskoj. Riječ je o sljedećim programima: Ciklus čitanja hrvatskih dramatičara u Comédie Française, izvedba predstave Car neuspjeha u Théâtre de Gennevilliers, te program Čitanja dramskog djela Slobodana Šnajdera: Peto evanđelje i Čitanja isječaka dramskih djela iż Antologije suvremenog dramskog teksta u sklopu Festivala Est-Ouest u gradu Die. Među gostima Hrvatskog centra ITI bio je savjetnik za književnost iz kazališta Comédie Française Laurent Muhleisen koji je bio odgovoran za odabir i koordinaciju programa "Ciklus čitanja hrvatskih dramatičara" u sklopu festivala Croatie, la voici. Gostovanje predstave Car neuspjeha potvrđeno je tijekom posjete predstavnika Festival d'Automne. Programi čitanja dramskog djela Slobodana Šnajdera Peto evanđelje i predstavljanje Antologije suvremenog hrvatskog dramskog teksta autorice Nataše Govedić posljedica su studijske posjete predstavnika Festivala Est-Ouest. Do tih suradnji je došlo zbog dolaska predstavnika Festivala d'Automne i Festivala Est-Ouest u dva navrata koji su tom prilikom izravno dogovarali gostovanja spomenutih predstava.

Od ukupno 29 osoba koliko je posjetilo Hrvatsku u sklopu studijskih posjeta, njih 7 su bili predstavnici potpornih institucija: Francuski institut i ONDA. Kako stoji u odgovorima jednog online upitnika koji je ispunio francuski ravnatelj kazališnog festivala, suradnju s hrvatskim partnerima su „ohrabrile povjerenice Festivala, predstavnici Francuskog instituta i organizacije ONDA koji su nakon studijske posjete poticali daljnje kontak-

${ }^{34}$ Citat iz korespondencije od 25. listopada 2011. godine, naslovljene na povjerenicu Festivala Seadetu Midžić, pohranjene u arhivama Ministarstva kulture Republike Hrvatske. 
te i osigurali dostavu dramskih predložaka hrvatskih autora koji su me interesirali" ${ }^{\prime \prime 2}$.

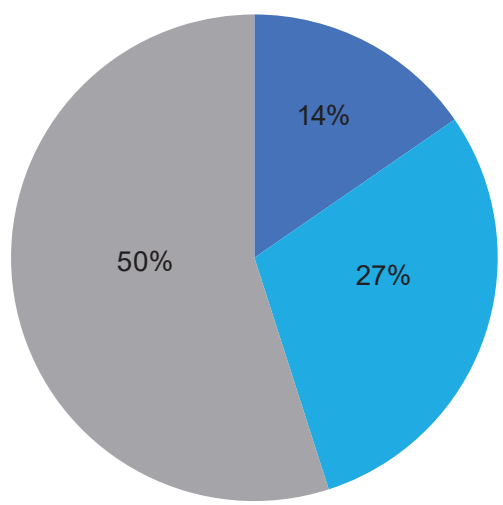

aktivni tijekom CLV $\square$ bez sudjelovanja u CLV

potporne institucije

Slika 3: Učinak studijskih posjeta

Iz analize organiziranih studijskih posjeta mogu se donijeti sljedeći zaključci: ukupno je organizirano 6 studijskih posjeta, od kojih je jedna bila grupna u formatu Showcasea, a preostalih pet s ciljanim boravcima za jedno do dvoje francuskih predstavnika. Od ukupno 29 francuskih profesionalaca koji su posjetili Hrvatsku, njih 23 je imalo prilike gledati predstave u sklopu organiziranog Showcasea. Ukupno je prikazano 12 kazališnih predstava, odnosno upriličeno je 15 izvedbi (jer su tri predstave imale po dvije izvedbe) koje su hrvatska produkcija te je izbor njih triju kasnije činio sastavni dio festivala Croatie, la voici. Tijekom studijskih posjeta nastupilo je 142 hrvatskih umjetnika, koji su uz izvođenje programa imali i tri zasebno organizirane prilike kako bi se otvorila mogućnost upoznavanja s francuskim profesionalcima. Tijekom ciljanih studijskih posjeta, devet je francuskih profesionalaca prvenstveno imalo organizirane sastanke s hrvatskim profesionalcima i predstavnicima kazališnih institucija. Od njih 9, samo jedna osoba kasnije nije bila uključena u provedbu festivala Croatie, la voici, što potvrđuje korisnost i potrebu za održavanjem ciljanih studijskih posjeta, kako bi se osigurao relevantan izbor programa za francusku javnost.

Studijskim je posjetima potaknuta mobilnost u području kulture jer su njihovim održavanjem potaknute suradnje, umrežavanje profesionalaca, otvaranje novih poslovnih mogućnosti, transfer znanja i upoznavanje francuskih profesionalaca s hrvatskim kazališnim izričajem te dramskim pismom. Od

${ }^{35}$ Citat iz odgovora jednog francuskog profesionalca na online upitnik koji je proveden. 
ukupnog broja pojedinaca koji su posjetili Hrvatsku u obliku studijskih posjeta, ukupno $41 \%$ je bilo kasnije uključeno u organizaciju događanja u sklopu Festivala. Kao posljedica održanih studijskih posjeta, tijekom festivala Croatie, la voici u jesen 2012. godine je održano ukupno sedam od petnaest programa koji su bili organizirani za područje kazališta i dramskog pisma, stoga se studijske posjete mogu ocijeniti kao pozitivna praksa ne samo zbog ostvarenih mobilnosti profesionalaca, nego i zbog činjenice da je francuska javnost bila upoznata s hrvatskim kazalištem i dramskim pismom, tijekom izvedbi spomenutih programa na festivalu Croatie, la voici. Preostalih osam programa koji su bili sastavni dio šireg programa festivala Croatie, la voici održano je uz podršku predstavnika potpornih institucija koje su tijekom studijskih posjeta imali priliku upoznati se sa sadržajima, osobama i institucijama koje su povezane s hrvatskim kazalištem i dramskim pismom, i na taj način potaknuti odražavanje tih programa u sklopu Festivala. U tom smislu, može se zaključiti kako su studijske posjete predstavnika potpornih institucija bile od koristi i nužnosti za poticanje mobilnosti unutar kulturnog sektora. Nadalje, može se zaključiti kako su pojedinačni studijski posjeti u konačnici potaknuli veći broj uvrštenih programa tijekom Festivala, jer su od njih pet, čak četiri posjeta okrunjena programima u sklopu Croatie, la voici.

Na Slici 1 prikazan je broj uspostavljenih suradnji u odnosu na broj pojedinaca koji su posjetili Hrvatsku tijekom priprema Festivala dok je na Slici 3 prikazan omjer za cjelokupni program povezan s kazalištem i dramskim pismom. Utvrđenim popisom studijskih posjeta i njihovih sudionika, ustanovljeno je kako je 27 \% profesionalaca od ukupnog broja koji su bili u studijskoj posjeti Hrvatskoj ostvarilo aktivnosti u sklopu festivala Croatie, la voici, 59 $\%$ sudionika nije imalo program tijekom Hrvatske kulturne sezone, dok je $14 \%$ sudionika bilo iz potpornih institucija ONDA i Francuskog instituta. Dobivenim podacima se potvrđuje kako je učinkovitost studijskih posjeta za programiranje kulturne sezone zadovoljavajuća jer je čak $41 \%$ sudionika studijskih posjeta bilo kasnije izravno uključeno u provedbu Festivala, uzevši $\mathrm{u}$ obzir kako su predstavnici potpornih institucija bili uključeni u kreiranje cjelokupnog programa. Od pet ciljanih posjeta u manjim grupama ili za pojedince tijekom pripreme Festivala, sudionici njih četiriju kasnije su bili izravno povezani s provedbom programa u sklopu Festivala, što govori u prilog činjenici kako je ciljana studijska posjet bolji format za potrebe programiranja kulturne sezone.

Za potrebe ovog rada, napravljena je analiza podataka o javnom financiranju koje se ostvaruje „Pozivom za predlaganje programa javnih potreba u kulturi“ Ministarstva kulture za razdoblje od 2009. do 2015. godine kako bi se mogao ustanoviti broj programa koji su ostvareni u pripremnim aktivnostima i za potrebe odražavanja programa tijekom festivala Croatie, la voici u Francuskoj u području kazališta i dramskog pisma uz podršku Ministar- 
stva kulture. U svakoj proračunskoj godini Ministarstvo kulture raspisuje Javne pozive za podršku kulturnom sektoru koje temeljem Zakona o kulturnim vijećima (Narodne novine, br. 48/04. i 44/09.) . $^{36}$ razmatraju stručna Vijeća te daju stručne podloge i mišljenja Ministarstvu kulture i ministru, temeljem kojih se odobravaju potpore. Napravljenom analizom, moguće je ustvrditi kako je u razdoblju od tri godine prije i poslije 2012. godine broj programa i sufinanciranja od strane Ministarstva kulture bio manji od godine provedbe Festivala. Uočava se odstupanje od te pojave u godini 2009., kada je podržano šest kazališnih programa u odnosu na osam programa u godini Festivala, a iznos potpore je bio veći: u 2009. godini je dodijeljeno 101 104,00 kuna u usporedbi s 104 840,68 kuna koliko je dodijeljeno za sufinanciranje kazališnih programa u godini Festivala. Za taj skok u odnosu na druge godine nije ustanovljen uzrok, niti je prepoznat razlog koji bi imao uporište u strateškom smjeru promišljanja. Moguće je zaključiti kako je u okviru Festivala hrvatske kulture u 2012. godini napravljen veliki iskorak $\mathrm{u}$ promociji hrvatskog dramskog pisma, jer u godinama prije i nakon toga nije bilo podržanih programa u tom području, dok je u 2012. godini podržano šest programa promicanje hrvatskog dramskog pisma u Francuskoj s iznosom 9789,75 kuna.

\section{Zaključak}

Razlike između tipova studije slučaja, tj. istraživačkih strategija nisu uvijek strogo određene i premda svaka strategija ima svoja razlikovna obilježja, velika su preklapanja među njima ${ }^{37}$. Ova studija slučaja se može okarakterizirati kao deskriptivna studija jer opisuje jedan fenomen $u$ okvirima njegova konteksta. Još preciznije klasificirano, uzimajući u obzir podjelu deskriptivne studije na tipičnu ili selektivnu (Hakim prema Schell: 1992), ova je studija tipična deskriptivna studija jer nema fokus samo na jedan određeni problem ili aspekt, nego teži produbljivanju znanja i što cjelovitijoj ilustraciji o temi, a kako bi osigurala bolje razumijevanje posljedičnih procesa. Pritom „deskriptivna teorija mora pokriti dubinu i širinu slučaja koji se istražuje ${ }^{\star 338}$.

Propitujući rezultate projekta Croatie, la voici u 2012. godini, ustanovljeno je kako je riječ o projektu koji je potaknuo mobilnost u kulturi te razmjenu iskustava i znanja među Francuskom i Hrvatskom. O tome svjedoče poda-

36 Posljednja izmjena donesena u lipnju 2013. godine.

$37 \mathrm{Uz}$ raznovrsne podjele, poput brojnih podjela na Lijphartove kategorije (1971: 691) ili Ecksteinove (1975: 95-123) najčešća citirana podjela po tipovima studija slučaja u obrađenoj literaturi jest podjela na tri tipa studija slučaja: na eksploratornu, eksplanatornu i deskriptivnu studiju (Yin, 2007).

38 W. Tellis: Introduction to Case Study. „The Qualitative Report“ 1997, br. 2 (3). 
ci analizirani $\mathrm{u}$ ovom radu, koji govore $\mathrm{u}$ prilog širokog dosega pripreme i provedbe kazališnih i dramskih programa u sklopu Festivala. Broj uključenih dionika, umjetnika, profesionalca i organizacija u kulturi koje su bile uključene $u$ pripremu i provedbu Festivala ukazuje na značaj provedenih programa. Koncept aktivnosti studijskih posjeta kao sastavni dio priprema kulturnih sezona potvrđen je kao primjer dobre prakse u poticanju mobilnosti u kulturnom sektoru jer je ostvarena mobilnost $\mathrm{u}$ tri prepoznata smjera: u kontekstu transfera znanja i poticanja interkulturnog dijaloga među profesionalcima u kulturi, stvaranja novih poslovnih mogućnosti i umrežavanja profesionalaca, te programiranja pojedinih programa u sklopu festivala Croatie, la voici, čime je francuska javnost dobila mogućnost upoznavanja s hrvatskim kazalištem i dramskim pismom. Transfer znanja i potaknuti interkulturni dijalog ostvareni su na način da je ukupno 29 francuskih stručnjaka imalo prilike pogledati 12 predstava, održati 34 individualnih sastanaka, upoznati 142 hrvatska glumaca, te produbiti odnose s hrvatskim i francuskim potpornim institucijama s kojima su nastavljene komunikacije o području hrvatskog kazališta i dramskog pisma ovisno o daljnjem interesu. Nove poslovne mogućnosti otvorene su aktivnostima umrežavanja tijekom studijskih posjeta, osiguranim informativnim materijalima na temu hrvatskog kazališta i dramskog pisma, te dostavljenim informativnim letcima prije i za vrijeme studijskih posjeta. U sklopu Festivala je ukupno prikazano 15 programa, što je francuskoj javnosti omogućilo priliku da se upozna s hrvatskim kazališnim izričajem i dramskim pismom. Osim izravne mogućnosti, kazalište i programi Festivala su bili predstavljani i komunikacijskim kanalima, čime je šira francuska javnosti dobila uvid u neka od imena hrvatskog kulturnog konteksta. Također, uvidom u analize proračunskih stavki, može se zaključiti kako je povećanje financijske podrške povezano s održavanjem Festivala. Ali činjenica da je u 2009. godini također bio veliki izdatak sredstava namijenjen upravo predstavljanju kazališnih programa u Francuskoj govori u prilog kako suradnja između Francuske i Hrvatske u ovom području ovisi o pojedinačnim inicijativama prije nego sustavnom i sistematičnom pristupu u planiranju. Provedeno istraživanje potvrđuje kako je mehanizam kulturnih sezona pozitivna praksa kojom se potiče mobilnost kroz koncept kulturne diplomacije.

\section{Literatura}

Ahearne J.: Cultural policy explicit and implicit: a distinction and some uses. „International Journal of Cultural Policy“ 2009, br. 2 (15), s. 141-153.

Chaubet F.: L'Alliance française ou la diplomatie de la langue (1883-1914). „Revue historique“ 2004, br. 4 (632), s. 763-785. 
Hancock D.-R., Algozzine R.: Doing Case Study Research: A Practical Guide for Beginning Researchers. New York, Teachers College Press, 2006.

Devin G.: Les diplomaties de la politique étrangère. U: Politiques étrangères. Nouveaux regards. Ur. C. Frederic. Paris 2002.

Jora L.: New practices and trends in cultural diplomacy. „Romanian Review of Political Sciences and International Relations“ 2013, sv. 10, br. 1. http://journal.ispri.ro/wp-content/uploads/2013/03/43-52-Lucian-Jora.pdf [pristup: 05.10.2017].

Kessler M.-C.: La politique étrangère de la France. Acteur et processus. Paris, Presses de Sciences Po, 1999.

Lombard A.: Politique culturelle internationale: Le modèle français face à la mondialisation. Arles, Actes Sud, 2003.

Mobility Matters: Programmes and Schemes to Support the Mobility of Artists and Cultural Professionals, Final Report. European Institute for Comparative Cultural Research gGmbH, 2008, http://ec.europa.eu/assets/eac/culture/policy/cultural-creative-industries/ documents/mobility-matters-report_en.pdf [pristup: 17.04.2019].

Painchaud P.: Fédéralisme et théories de politique étrangère. „Études internationales“ 1974, br. 1 (5), s. 25-44, https://core.ac.uk/download/pdf/59600212.pdf [pristup: 17.04.2019].

Poirrier P.: Politiques et pratiques de la culture. Paris, La Documentation française, 2010.

Pičuljan Z.: Diplomacija kao državna služba. Zagreb, Društveno veleučilište u Zagrebu, 2007.

Rigaud J.: Les relations culturelles extérieures: Rapport au ministre des Affaires étrangères. Paris, La Documentation française, 1980.

Roksandić D.: "Croatie, la voici“ 22. festival Est-Ouest, Die (departman Drôme), 19.-30. rujna 2012., posvećen Hrvatskoj. „Radovi - Zavod za hrvatsku povijest“ 2013, br. 1 (45), s. $265-278$.

SCHIFfler Lj.: Europski kontekst hrvatske kulture i diplomacije (povijesno-filozofski pristup). U: Rad HAZU. Knj. 492. Razred za društvene znanosti 43, 2005, s. 235-239.

Schneider C.-P.: Cultural Diplomacy: Hard to define, but you'd know it if you saw it. "The Brown Journal of World Affairs" 2006, br. 1 (13), s. 191-203.

Scullion A., Garcia B.: What is Cultural Policy Research? „International Journal of Cultural Policy Research“ 2005, br. 11 (2), s. 113-127.

Singh J.-P.: International Cultural Policies and Power. Palgrave Macmillian, 2010.

Sкоко B.: Hrvatska, image, identitet, promocija. Zagreb, Školska knjiga, 2005.

STAKE R. E.: Qualitative research: Studyng How things work, strategies of qualitative inquiry. New York, The Guilford Press, 2010.

Tellis W.: Introduction to Case Study. „The Qualitative Report“ 1997, br. 2 (3).

YIN R. K.: Studija slučaja - dizajn i metode. Zagreb, Fakultet političkih znanosti, 2007. 